\title{
The use of low-cost measuring devices for testing air quality in hard-to-reach locations
}

\author{
Mariusz Rogulski ${ }^{1, *}$ \\ ${ }^{1}$ Warsaw University of Technology, Faculty of Building Services, Hydro and Environmental \\ Engineering, Nowowiejska 20, 00-653 Warsaw, Poland
}

\begin{abstract}
Air quality assessment is traditionally carried out by ground monitoring. With the development of technology and the creation of small, low-cost sensors, it became possible to effectively study lower tropospheric layers by using light aircraft and balloons. The article presents the use of designed small, portable devices using low-cost dust sensors to research air pollutants with using a hot air balloon. The results of measurements of $\mathrm{PM}_{10}$ concentration using tethered balloon flights and during free flight are presented.
\end{abstract}

\section{Introduction}

Clean air is considered a fundamental factor for human health and well-being. It is treated by the United Nations as one of the goals of sustainable development [1]. Air pollution is a serious threat to human health around the world and is a critical environmental quality issue that cannot be neglected in Europe [2].

In order to test the air quality, its monitoring is carried out. Historically, air quality monitoring has been carried out for two main purposes: legislative supervision and scientific research. The general framework for modern official monitoring of air quality is stated by the law and the resulting legislation. One of the more important examples of legal acts is the European CAFE Directive (Directive 2008/50 / EC of the European Parliament and the Council of 21 May 2008 on air quality and cleaner air for Europe).

Poor air quality is a big problem for many large city agglomerations [3]. The control of air pollution and the monitoring of its quality makes it possible to implement emission reduction strategies and stimulate environmental awareness among citizens. Air pollution monitoring can be carried out by various techniques using a variety of technologies [4]. One of these strategies is to use data from appropriately located conventional monitoring stations to assess compliance with air quality legislation, study of exposure to pollutions, support air quality management and plan appropriate actions. Conventional air pollution monitoring systems mainly use stationary measuring devices. They are based mainly on sophisticated and well-known instruments and measurement methods [5]. In order to guarantee the accuracy and quality of data, these instruments use complex measurement methods and many auxiliary tools, such as temperature controllers, relative humidity regulators, air filters and calibrators. Owing to it, monitoring stations are highly reliable,

* Corresponding author: Mariusz.Rogulski@pw.edu.pl 
accurate and capable of measuring a wide range of pollutants. Data on air pollution in places without monitoring stations are obtained based on models or estimates of air quality [6].

The reference instruments used in traditional, automatic air quality monitoring stations are very expensive and require regular maintenance. For these reasons, the number of monitoring stations for air quality is generally small, and the resolution of observations is insufficient to allow detailed spatial representation of air quality. For example, in Poland there are just over 200 automatic stations belonging to voivodeship inspectorates of environmental protection. In Warsaw, information on concentrations of pollutants in the air is provided by 8 automatic stations (including 5 owned by Masovia voivodeship inspectorate of environmental protection) and 3 manual stations. So, the average area per one station in the capital is over $100 \mathrm{~km}^{2}$, and on the national scale - over $3000 \mathrm{~km}^{2}$.

Other major disadvantage of traditional measuring stations is usually limitation to the environment close to station location. Due to their dimensions and weight, they cannot usually be used in places where mobility is required, for example, higher above the ground surface or at sea.

Currently, there is a worldwide tendency to collect real-time air quality data that can be used to provide detailed spatial and temporal information to complement existing air quality monitoring networks and support decision-making and public information [7]. In order to increase the spatio-temporal resolution of information on air pollution, scientists are trying to expand the possibilities of measurement networks by using, in addition to traditional devices, also low-cost sensors, which due to advanced technologies become more and more accessible, and at the same time have small sizes and fast response time. Owing to them, information on air pollution can be updated in a few minutes or even seconds [8]. Devices based on low-cost sensors offer mobility, easy configuration and reconfiguration of measuring nodes and the possibility of air measurements in places where the use of conventional devices is very difficult or impossible.

This article presents the use of designed small, portable devices with low-cost dust sensors to study particulate matter concentration with using a hot air balloon. Section 2 describes the device built for testing with hot air balloon. Section 3 contains the results of measurements made using the designed device. The last section includes conclusions.

\section{Materials and methods}

The prototypes of devices, based on low-cost sensors, have been developed by researchers from the Warsaw University of Technology. The purpose of the research was, among others, the use of modern or non-standard technologies and carriers for placing and moving measuring devices (e.g. balloon, drone, ship), and thus the possibility of verify air quality in hard-to-reach locations, where the use of conventional measuring devices is difficult or even impossible.

The developed device (Fig. 1) consisted of the following components:

- microcontroller - Arduino Mega,

- $\quad$ sensors: particulate matter $\mathrm{PM}_{10}, \mathrm{PM}_{2.5}, \mathrm{PM}_{1}$, temperature and humidity,

- communication module - a modem using GPRS for immediate data transfer to the central server,

- location module-GPS,

- battery - providing power to the measuring device,

- auxiliary electronic components responsible for the required level of system power supply and signal transmission. 


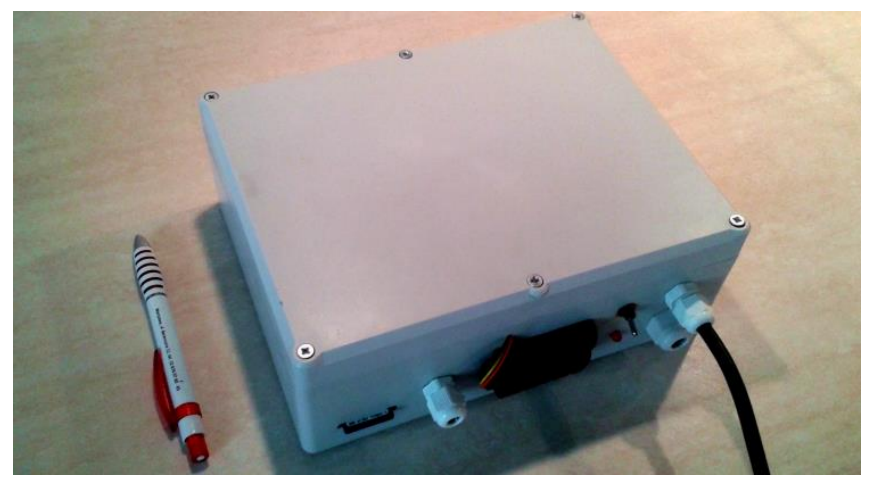

Fig. 1. Measuring device.

There are many models of sensors measuring air parameters and new models are still being developed [9]. Recently, low cost sensors for dust measurements have been the most interest. The reason is that media and social campaigns (in the form of various "smog alarms") increase awareness of the problem of air pollution with dusts, the sources of these pollutants, as well as the methods of measuring and interpreting the measured values. Secondly, the measurements of air pollutions until recently were reserved for professionals and possible only with expensive, professional equipment. Owing to low-cost devices, with greater or lesser accuracy, it is now practically possible for anyone interested in this topic.

Modern sensors offer the potential to accumulate large amounts of high-resolution air quality data, but the quality, durability and accuracy of particularly low-cost sensors is subject to intensive research [10]. Especially in the last few years a number of scientific articles have been published in this area. Both sensors and complete devices using low-cost sensors are tested in laboratories and in real conditions. For example - in [11, 12] PM sensors were tested in specific applications and in $[13,14]$ in laboratory conditions. These tests are promising for PM sensors. Analyses have shown that, in many cases, low-cost sensors are correlated with professional instruments. However, it should be also remembered that sensors of this type have some drawbacks - they are not as accurate as the reference methods, some have limited sensitivity and may be affected by many other factors such as humidity. Often sensors of this same manufacturer and from the same series give different values of measurements [15].

A DFRobot low-cost particulate matter sensor was used to build the prototype device. Research of this company sensors has been carried out since 2015. In order to determine the characteristics of sensors and the effect of some meteorological parameters on the quality of results, comparative measurements were carried out with a reference device as part of the campaign carried out by the Małopolskie Marshal's Office, Polish National Reference and Calibration Laboratory of the Main Inspectorate for Environmental Protection, AGH University of Science and Technology in Kraków, the Kraków Smog Alert, in cooperation with the Voivodeship Environmental Protection Inspectorate in Kraków and the municipality of Rabka-Zdrój. The research was conducted at the station of the National Reference and Calibration Laboratory of the Main Inspectorate of Environmental Protection from February 15 to June 15, 2017 in Rabka-Zdrój. In addition, a prototype measuring network consisting of 9 devices was built in the town of Nowy Sącz. The network exists since autumn 2016. Conclusions from the operation of the network and measuring devices can be found in $[16,17]$.

Because the used sensors make possible to carry out measurements continuously, the results can be available in real time. For this purpose, the devices have been equipped with a GSM module using a cellular network to send results to the central server. To track the device's location when it is placed on a mobile carrier, a GPS module has been added. In 
addition to the geographical position, it also allows to determine the height of the device above sea level during the flight. The measurements were pre-aggregated in the measuring device and then sent to the database every dozen seconds. Access to the data took place either directly on the server or via a dedicated website. The high frequency of measurements and the transmission of results emerged from the rapid movement of the device. The device presented in this article can also be mounted on the drone, so that the frequency of sending results can be even more important than in the case of a balloon (due to the potential for a higher speed of drone).

\section{Results}

Conducted experiments relied on placing the constructed device outside the hot air balloon gondola, and then making many takeoffs and flights. The fuel used to heat the air in the balloon was gas. The aim of the research was to examine the possibility of using a balloon to study air quality much higher above the ground surface than other methods allow (e.g. drones). The use of a balloon as a carrier of a measuring device is burdened with several limitations - e.g. a large, unobstructed area from which the balloon can be lifted is needed, appropriate permits are required, the trajectory of the flight must be such that it avoids all obstacles from afar. The balloon does not provide such flight possibilities as a drone, but allows to rise higher and further than using a drone. The rise of the balloon can take place when the balloon is tethered - in this way it can be analyzed the changes in pollution depending on the altitude in about the same place. In turn, during free flight, it is possible to conduct tests at higher altitudes, however the direction of flight is largely determined by the direction and strength of the wind.



Fig. 2. On the left - measurements using the tethered balloon, on the right - during free flight.

Balloon measurements were repeatedly performed. Most often they were carried out using a tethered balloon, which limited the altitude of flight to about 30-40 meters above ground level. There were also made several free flights. Balloon research was possible owing to cooperation with pilots from Gaspol Energy Team.

Measurements using a tethered balloon were conducted at various locations during spring and autumn of 2017. One of them was in the western part of the Warsaw-Babice airport. Research in this area was carried out mainly at the end of March 2017. During 10 takeoffs and landings in the late-afternoon and evening hours (between 5 and $8 \mathrm{pm}$ ), it 
was examined how the PM10 dust concentration changes depending on the height above ground level. The balloon rises to an average height of 30 meters above ground level with average speed $0.5-1 \mathrm{~m} / \mathrm{s}$. The determined average values of PM10 concentration for $28^{\text {th }}$ of March 2017 on the basis of 10 takeoffs and landings has been presented in Fig. 3.



Fig. 3. Average value of $\mathrm{PM}_{10}$ concentration $\left[\mu \mathrm{g} / \mathrm{m}^{3}\right]$ depending on the altitude $[\mathrm{m}]$ above ground level for measurements made with tethered balloon on $28^{\text {th }}$ of March 2017 in the Warsaw-Babice airport.

The analysis makes possible to find the answer to the question - how the $\mathrm{PM}_{10}$ concentration changes depending on the height above the ground level? The area in which the study was conducted is characterized by the occurrence of low emission sources (especially to the west of the airport). On the day of the survey, in the evening hours the temperature was low and the wind was weak, therefore the impact of this type of sources on the level of air pollutions was undoubtedly significant (which was also confirmed by direct observations). The measurements show that the more or less constant level of contaminations was maintained at a height of about 18 meters - the obtained values fluctuated around $35-37 \mu \mathrm{g} / \mathrm{m}^{3}$. Higher, the value of contaminations with particulate matter gradually decreased reaching the value below $20 \mu \mathrm{g} / \mathrm{m}^{3}$ at a height of 28 meters. It can be assumed that on this day and in the vicinity of the examined location, low emission pollutants reached just approx. 20 meters above the ground surface.

Besides tests with using a tethered balloon, several free flights were also conducted. One of the most interesting cases was the one in the evening of $30^{\text {th }}$ August 2017 in Nowy Targ. The approximate flight trajectory is shown in Fig. 4. The distance from the starting to the landing point was about $2.5 \mathrm{~km}$.

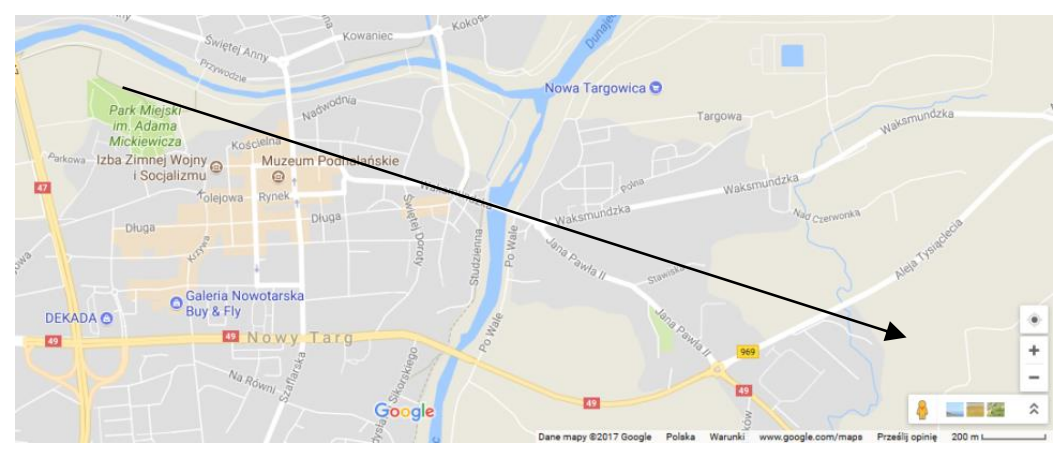

Fig. 4. The approximate flight trajectory during balloon flight on $30^{\text {th }}$ of August 2017 in Nowy Targ. 
Fig. 5 presents the measured concentration of $\mathrm{PM}_{10}$ depending on the height above the ground level and time. The altitude was determined on the basis of GPS data and data on altitude with using Google maps.

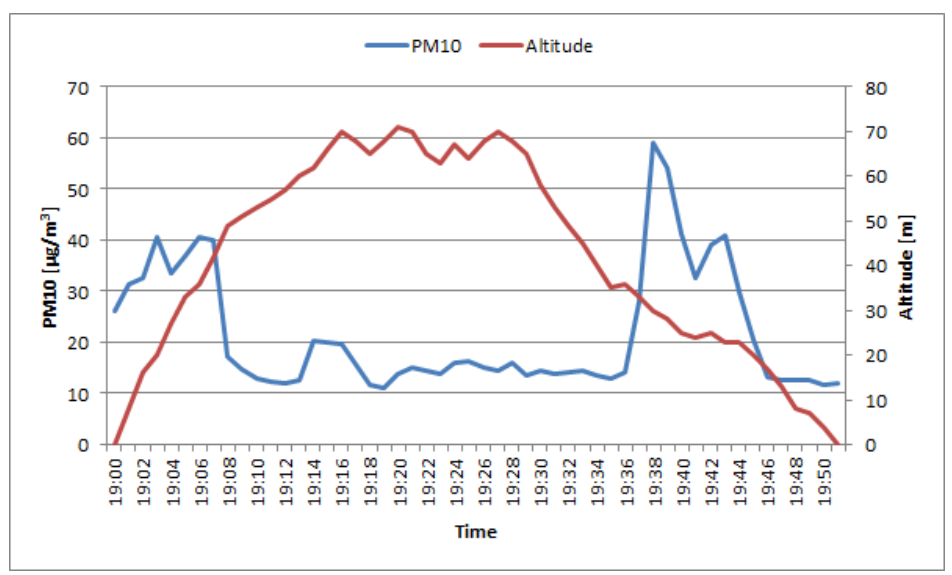

Fig. 5. Measured concentration of $\mathrm{PM}_{10}\left[\mu \mathrm{g} / \mathrm{m}^{3}\right]$ depending on the height above ground level $[\mathrm{m}]$ and time.

$30^{\text {th }}$ of August 30 in Nowy Targ was warm with a maximum temperature over $25^{\circ} \mathrm{C}$, almost windless. During the day, the concentration of $\mathrm{PM}_{10}$ oscillated around $10 \mu \mathrm{g} / \mathrm{m}^{3}$. However, the evening of the day was cold and smoke began to emerge from the chimneys of the houses near the starting area of the balloon (the playing field at the Mickiewicz's Municipal Park). During the start of the balloon the concentration of particulate matter was about $30-40 \mu \mathrm{g} / \mathrm{m}^{3}$. The balloon rose quite quickly and this concentration was maintained to a height of about $40 \mathrm{~m}$ above ground level. Above this height concentrations dropped significantly and ranged between 10 and $20 \mu \mathrm{g} / \mathrm{m}^{3}$. Such values have been maintained for the next minutes, when the balloon held its maximum altitude, as well as when it began to descend. The particulate matter concentration increased significantly and rapidly at approx. 19:37, when the balloon lowered below $35 \mathrm{~m}$ above ground level. He was then above the area between Waksmundzka Street and John Paul II Avenue, where there are many sources of low-emission. During the last four minutes of the flight were again small values of pollutions, because the balloon was above the green area, devoid of smoke sources. Probably dust emitted from chimneys (due to very low wind) had not yet been able to move over this area.

The carried out measurements show that during the flight the height of particulate matter coming from low emission, in the case of flight over such areas, reached approx. $30 \mathrm{~m}$ above ground level. It should be taken into account that during the measurements, dust emission from domestic furnaces has just started, as well as the fact that the vicinity of Nowy Targ is characterized by a more diversified terrain than, for example, Warsaw.

\section{Conclusions}

Based on a dozen or a few dozen flights, of course, we cannot determine the regularity in values and in the displacement of pollutants. What can be said on this basis is that a balloon with a measuring device can also be an effective transport medium for analyzing the vertical spread of particulate matter and other gases in the atmosphere. Higher altitude tests can be conducted during a free flight, while for lower altitudes a better solution is to use a tethered balloon. The advantage of the balloon, in comparison, for example, to the drone, 
is potentially a higher height at which the air quality can be tested, the possibility of presence an operator who can perform additional measurements with manual devices and a higher payload (even several dozen kilograms of additional equipment).

In this case, the use of the drone can be difficult. On the other hand, balloon takeoff requires much more terrain without obstacles, is much more expensive (than the use of a drone), requires several people (when unfolding and folding the balloon) and the direction and speed of flight is strongly dependent on the strength and direction of the wind. Both in the case of a balloon and a drone, certain atmospheric conditions are desirable - weak wind, no other violent atmospheric. phenomena, and in the case of a balloon - sometimes the right time of day.

\section{References}

1. UN, United Nations Open Working Group on Sustainable Development Goals (2015)

2. European Environment Agency, Air Quality in Europe - 2013 Report. (EEA Report, 9/2013)

3. A. Baklanov, L. Molina, M. Gauss, Atmos. Environ. 126, 235-249 (2016)

4. M. Penza, D. Suriano, M. Villani, L. Spinelle, M. Gerboles, IEEE Sensors, 2012-2017 (2014)

5. L. Amorim, J. Carneiro, Z. Cardeal, J. Chromatogr. B 865, 141-146 (2008)

6. M. Bravo, M. Fuentes, Y. Zhang, M. Burr, M. Bell, Environ. Res. 116, 1-10 (2012)

7. I. Heimann, V. Bright, M. McLeod, M. Mead, O. Popoola, G. Stewart, R. Jones, Atmos. Environ. 113, 10-19 (2015)

8. Y. Ma, M. Richards, M. Ghanem, Y. Guo, J. Hassard, Sens. 8, 3601-3623 (2008)

9. E. Snyder, T. Watkins, P. Solomon, E. Thoma, R. Williams, G. Hagler, D. Shelow, D. Hindin, V. Kilaru, P. Preuss, Environ. Sci. Technol. 47, 11369-11377 (2013)

10. A. Lewis, Nature 535, 29-31 (2016)

11. M. Gao, J. Cao, E. Seto, Environ. Pollut. 199, 56-65 (2015)

12. D. Holstius, A. Pillarisetti, K. Smith, E. Seto, Atmos. Meas. Tech. 7, 1121-1131 (2014)

13. Y. Wang, J. Li, H. Jing, Q. Zhang, J. Jiang, P. Biswas, Aerosol Sci. Technol. 49, 1063-1077 (2015)

14. E. Austin, I. Novosselov, E. Seto, M. Yost, PLoS One, 10, e0137789 (2015)

15. M. Isaac, Environ. Manage 7, 32-37 (2014)

16. M. Rogulski, Ener. Proc. 128, 437-444 (2017)

17. M. Rogulski, B. Dziadak, Proceedings of the $3^{\text {rd }}$ International Conference on Geographical Information Systems Theory, Applications and Management - Volume 1: GISTAM, 307-314 (2017) 